\title{
Decoupling of economic growth and emissions in China's cities: a case study of the Central Plains urban agglomeration $^{1}$
}

\author{
$\mathrm{Li} \mathrm{Li}^{1,2,3,4}$, Yuli Shan ${ }^{2, *}$, Yalin Lei ${ }^{1,3^{*}}$, Sanmang $\mathrm{Wu}^{1,3}$, Xiang $\mathrm{Yu}^{5}$, Xiyan Lin ${ }^{6}$, Yupei \\ Chen $^{7}$
}

${ }^{1}$ School of Economics and Management, China University of Geosciences, Beijing 100083, China

${ }^{2}$ School of International Development, University of East Anglia, Norwich NR4 7TJ, UK

${ }^{3}$ Key Laboratory of Carrying Capacity Assessment for Resource and Environment, Ministry of Natural Resources of the People's Republic of China, Beijing 100083, China

${ }^{4}$ State Key Laboratory of Water Resource Protection and Utilization in Coal Mining, Beijing 100011, China

${ }^{5}$ Institute for Urban and Environmental Studies, Chinese Academy of Social Sciences, Beijing 100028, China

${ }^{6}$ China Science and Technology Exchange Center, Beijing 100045, China

7 School of Economics, Minzu University of China, Beijing 100081, China

${ }^{*}$ Corresponding authors: y.shan@uea.ac.uk (Shan YL); leiyalin@ cugb.edu.cn (Lei YL)

\begin{abstract}
\footnotetext{
${ }^{1} \mathrm{Li} \mathrm{Li}$ analyzed the data and wrote the manusript;

Yuli Shan guided to analyze the data;

Yalin Lei and Yuli Shan designed the research together;

Sanmang $\mathrm{Wu}$ and Xiang Yu put forward some advice in the results analysis;
}

Xiyan Lin and Yupei Chen contributed new analytic ideas in the revised paper.
\end{abstract}

Recently, the economy has grown rapidly in China's Central Plains urban agglomeration, with high energy consumption and a huge pressure on reducing $\mathrm{CO}_{2}$ emissions. Thus, low-carbon development is an important measure to solve economic, energy and environmental problems. To analyse low-emission development, this paper clarifies the evolutionary characteristics of $\mathrm{CO}_{2}$ emissions and the decoupling relationship between GDP and $\mathrm{CO}_{2}$ emissions based on the latest available data from 2000 to 2015. The results indicate that $\mathrm{CO}_{2}$ emissions of Pingdingshan and 
Changzhi are higher in the same year. The ratios from coal consumption accounting for the total $\mathrm{CO}_{2}$ emissions are clearly bigger than from other energy types and industrial processes. Changzhi, Luoyang and Pingdingshan have reached their peaks. Five cities have experienced strong decoupling after 2010, 13 cities present weak decoupling, 4 cities present growth connection, and 7 cities show growth negative decoupling. It can be concluded that a relatively smaller proportion of industry and strict policy implementations of coal reduction are the main factors in inhibiting the decoupling. So the proportion of coal purification should be increased firstly. Then, the energy consumption structure should be changed from the traditional coal consumption structure to coal, oil and gas. Lastly, economic means can be used to control $\mathrm{CO}_{2}$ emissions.

Keywords: $\mathrm{CO}_{2}$ emissions; Emission intensity; Per capita $\mathrm{CO}_{2}$ emissions; Decoupling analysis

\section{Introduction}

Climate change is a common challenge and core issue faced by humans in the 21 st century. Tackling climate change and promoting green and low-carbon development are worldwide concerns. Compared to other nations, China has the highest carbon dioxide $\left(\mathrm{CO}_{2}\right)$ emissions in the world [1]. As a responsible developing country, China regards low-carbon development not only as an international obligation to actively address climate change but also as an inherent requirement to achieve its sustainable development. In 2009, the government proposed to reduce the per capita $\mathrm{CO}_{2}$ emissions of the gross domestic product (GDP) by $40 \%$ to $50 \%$ by 2020 compared with 2005 [2]. The National Development and Reform Commission also proposed to develop low-carbon industries and build low-carbon cities in July 2010 [3]. To address the growing urbanization and urban greenhouse gas emissions, China has launched the Climate Smart/Low-Carbon cities initiative [4]. The Chinese central government also mentioned that China would try to reach its $\mathrm{CO}_{2}$ emissions peak in 2030 and strive to achieve this goal as soon as possible in the climate change conference in Paris in November 2015 [5]. The Global Carbon Project released the Global Carbon Budget report at the UN Climate Change Conference in Bonn in November 2017, which mentioned that China's $\mathrm{CO}_{2}$ emissions accounted for $28 \%$ of the world's emissions in 2016, more than a quarter of the world's total $\mathrm{CO}_{2}$ emissions [6]. 
The urbanization rate in China has changed rapidly from $17.92 \%$ in 1978 to $58.52 \%$ in 2017 [7]. China's urbanization process will proceed at a high speed in the next decade or more. Cities are places of high energy and resource consumption, and they are also the places of greenhouse gas emissions. They cover only $2 \%$ of the earth's surface, but the greenhouse gas emissions from cities account for $80 \%$ in the total gas emissions $[8,9]$. Cities play important roles in tackling the challenges of global climate change, and they will still be the main source of China's $\mathrm{CO}_{2}$ emissions growth in the future [10]. Therefore, accurate accounting of urban $\mathrm{CO}_{2}$ emissions is the first and most important step in implementing emissions reduction policies and measures. The scientific and reasonable accounting of $\mathrm{CO}_{2}$ emissions is the foundation for formulating emission reduction strategies. Many scholars have calculated $\mathrm{CO}_{2}$ emissions at the national or provincial scale and at the sector or industries scale. Shan et al. [11] calculate the provincial $\mathrm{CO}_{2}$ emissions in China from 2000 to 2012 and found that Shandong contributed most to national emissions accumulatively. Shan et al. [12] estimated China's CO2 emissions from 1997 to 2015 and offered data base for further emission reduction research in China. Mi et al. [13] adopted the input-output model to account $\mathrm{CO}_{2}$ emissions for 13 China's cities from consumption angle and found substantial differences between production- and consumption-based accounting. Using an integrated model of economy and climate, Mi et al. [14] considered China might reach its peak $\mathrm{CO}_{2}$ emissions at $11.20 \mathrm{Gt}$ in 2026. Mi et al. [15] compiled China's 2012 multiregional input-output table and structural decomposition analysis to investigate the driving factors embodied in China's $\mathrm{CO}_{2}$ emissions from 2007 to 2012. And the results indicatedvthat emission flow patterns had changed greatly since the financial crisis. Meng et al. [16] showed the emissions embodied in exports from less-developed regions such as Vietnam and Bangladesh have surged. Shan et al. [17] calculated $\mathrm{CO}_{2}$ emissions from China's lime production from 2001 to 2012 and found lime production was a big emission source. Using data representing 637 Chinese cities, Ramaswami et al. [18] considered cross-sectoral strategies to be helpful, and they could contribute an additional 
$15 \%-36 \%$ to $\mathrm{CO}_{2}$ mitigations. $\mathrm{Li}$ et al. [19] comprehensively evaluated $\mathrm{CO}_{2}$ emissions in Beijing and demonstrated that emission intensity, production input and output structure change contributed to decreasing $\mathrm{CO}_{2}$ emissions. Shan et al. [20] presented a new, city-level calculation of $\mathrm{CO}_{2}$ emissions for 182 Chinese cities, and the results demonstrated that more affluent cities had relative lower $\mathrm{CO}_{2}$ emissions per unit GDP. Many scholars are also using the decoupling method to analyse the relationship between economics and the environment or resources.

Decoupling means that there is no correlation state. In recent years, China's cities have shown a rapid growth trend, but the pressure of growing $\mathrm{CO}_{2}$ emissions also comes with economic growth. The Organisation for Economic Co-operation and Development (OECD) first proposed the theory of breaking the decoupling of economic growth from resource consumption or environmental pollution [21], and it also analysed the degree of equilibrium between agricultural policy and markets [22]. Based on the decoupling theory, Vehmas et al [23] compared the ratio of the rate of the change in economic growth and the change in environmental pressure using environmental Kuznets curve hypothesis. The results showed that the EU shows strong de-linking in 1973-1999, Japan, USA and China weak de-linking and India and Brazil expansive re-linking. Shuai et al [24] investigated the global decoupling of GDP from total carbon emission, carbon intensity and carbon emission per capita by using Tapio decoupling index and the data from 2000 to 2014. The results showed the countries whose economic growth having decoupled from carbon intensity, carbon emission per capita, and total carbon emission, account for $74 \%, 35 \%$ and $21 \%$ respectively. And higher income-level countries had the larger proportion of countries having reached the decoupling. Juknys et al [25] discussed the relationship between economic growth and resource utilization in New Eastern EU members from 1991 to 2002, and they named the decoupling of economic growth and resources as the primary decoupling and the decoupling of resource and environmental pollution as the secondary decoupling. The results indicated that further decoupling maintained 
between environmental impact and economy growth. Tapio [26] calculated the relationship between the development of the European transport industry and economic growth from 1997 to 2001 and introduced the Tapio decoupling elastic method into the accounting of the relationship among economic growth, resources and the environment. The results indicated that weak decoupling lied in the relationship between transport $\mathrm{CO}_{2}$ emissions and GDP. Enevoldsen et al [27] analyzed the impact of energy prices and taxes on $\mathrm{CO}_{2}$ emissions in ten industrial sectors in three Scandinavian countries using decoupling from 1991 to 2001. The results found that long-term elasticities for industries were higher than normally assumed. Profillidis et al [28] analyzed the coupling and decoupling relationships between transport-related energy consumption and GDP in the European Union (EU)-28 member countries. The results indicated that the relationship was clearly different before and after the economic crisis of 2008. Halicioglu and Ketenci [29] performed on the relationship between output, renewable and non-renewable energy production, international trade, capital and labour for the EU-15 countries from 1980 to 2015. The results demonstrated the cointegration relationships existed in the seven countries of the EU-15.

Domestic studies on decoupling have mainly focused on the relationships between economic growth and energy consumption, environmental pollution, $\mathrm{CO}_{2}$ emissions and water resource consumption. Wang and Yang [30] calculated the decoupling relationship between industrial development and economic growth in the Beijing-Tianjin-Hebei region from 1996 to 2010 using Logarithmic Mean Divisia Index and Tapio index. The results indicate that weak decoupling was the main characteristic from 1996 to 2000 and from 2006 to 2010, strong decoupling in 2007, weak coupling in the period of 2001-2005. Xia and Zhong [31] constructed the decoupling elastic coefficient model and Environment Kuznets Curve (EKC) model in 271 China's cities and found that the tipping point of relative decoupling and absolute decoupling was at the turning point of EKC from 2004 to 2013. Qi and Chen [32] 
calculated the decoupling relationship between economic growth and energy, resources and pollutant emissions using Tapio index from 1999 to 2010. Taking Chongqing as an example, the results showed high energy consumption sector was weak decoupling. Wu et al [33] discussed the decoupling states between China's transport development and its $\mathrm{CO}_{2}$ emissions from 1994 to 2012. The results demonstrated that China's transport sector was far from the decoupling state. Existing decoupling studies mainly focus on the measurement and evaluation of decoupling degree (table 1). Decoupling analysis can be carried out on micro level and the planning in the related fields in the future.

\section{Table 1}

Literature review on decoupling

\begin{tabular}{|c|c|c|c|}
\hline Author & Period & Research object & Result \\
\hline $\begin{array}{l}\text { Vehmas et } \\
\text { al (2003) }\end{array}$ & 1973-1999 & The EU & $\begin{array}{l}\text { The EU was strong de-linking in the period of } \\
\text { 1973-1999, Japan, USA and China weak } \\
\text { de-linking and India and Brazil expansive } \\
\text { re-linking. }\end{array}$ \\
\hline Shuai $\mathrm{C}$, & $2000-2014$ & The world & The countries whose economic growth \\
\hline Chen X, & & & decoupled from carbon intensity, carbon \\
\hline $\begin{array}{l}\text { Wu Y, et } \\
\text { al (2009) }\end{array}$ & & & $\begin{array}{l}\text { emission per capita, and total carbon emission, } \\
\text { account for } 74 \%, 35 \% \text { and } 21 \% \text { respectively. }\end{array}$ \\
\hline $\begin{array}{l}\text { Juknys et } \\
\text { al (2005) }\end{array}$ & 1991-2002 & $\begin{array}{l}\text { New Eastern EU } \\
\text { members }\end{array}$ & $\begin{array}{l}\text { Further decoupling maintained between } \\
\text { environmental impact and economy growth. }\end{array}$ \\
\hline $\begin{array}{l}\text { Tapio } \\
(2005)\end{array}$ & $1997-2001$ & $\begin{array}{l}\text { the European } \\
\text { transport industry }\end{array}$ & $\begin{array}{l}\text { Weak decoupling lied in the relationship } \\
\text { between transport } \mathrm{CO} 2 \text { emissions and GDP. }\end{array}$ \\
\hline $\begin{array}{l}\text { Enevoldse } \\
\mathrm{n} \quad \text { et } \text { al }\end{array}$ & $1991-2001$ & Scandinavian & $\begin{array}{l}\text { Long-term elasticities for industries were higher } \\
\text { than normally assumed. }\end{array}$ \\
\hline
\end{tabular}


(2007)

Profillidis

et al

(2018)

Ferda and 1980-2015 the

Natalya

(2018)

Wang and 1996-2010 Beijing-Tianjin-H Weak decoupling was the main characteristic Yang

(2015)

Xia and 2004-2013 271 China's cities

Zhong

(2016)

Qi and 1999-2010 Chongqing

Chen

(2012)

Wu et al 1994-2012 China's transport China's transport sector was far from the (2018) countries

the European The relationship was clearly different before and

Union (EU)-28 after the economic crisis of 2008.

member countries

EU-15 The cointegration relationships existed in the seven countries of the EU-15. strong decoupling in 2007, weak coupling in the period of 2001-2005

The tipping point of relative decoupling and absolute decoupling was at the turning point of EKC from 2004 to 2013.

High energy consumption sector was weak decoupling. decoupling state.

From the literature above, it can be seen that not all cities have an estimation of $\mathrm{CO}_{2}$ emissions. There are currently, few $\mathrm{CO}_{2}$ emissions accounting for the Central Plains urban agglomeration have been estimated. Meanwhile, the Central Plains urban agglomeration is also under great pressure to reduce $\mathrm{CO}_{2}$ emissions. Therefore, based on the method developed by the China Emission Accounts and Datasets (CEADs) team [34], this paper estimates the $\mathrm{CO}_{2}$ emissions from 2000 to 2015, which can 
provide the data base for the formulation of emission reduction policies and other relevant studies for the Central Plains urban agglomeration. We have updated the data in China Emission Accounts and Datasets (CEADs) at http://www.ceads.net. Those who wish to replicate the results of this study can download the data for free. Meanwhile, the current decoupling theory is mainly applied at the national, regional or sector level, with little attention paid to urban agglomerations, especially the Central Plains urban agglomeration. Therefore, this paper takes the Central Plains urban agglomeration as a case, selecting $\mathrm{CO}_{2}$ emissions and economic growth as the main indicators to measure the degree of decoupling of urban economic growth from $\mathrm{CO}_{2}$ emissions, which could provide suggestions for the realization of decoupling in 29 cities in the Central Plains urban agglomeration.

\section{Method and data}

\section{1 $\mathrm{CO}_{2}$ emissions accounting boundary}

The Central Plains urban agglomeration was intended to be a national urban agglomeration with high resource allocation efficiency, strong economic vitality, competitiveness and influence. The Central Plains urban agglomeration is the key to the implementation strategy of promoting the rise of the central region, providing strategic support for the construction of the "The Belt and Road Initiative" and promoting the coordinated development between the East and the West. It is located in central China, which is the largest, most integrated and most densely populated urban agglomeration among the Yangtze River Delta, the Pearl River Delta and the Beijing-Tianjin-Hebei region. It covers 30 cities in Henan, Shanxi, Hebei, Shandong and Anhui [35]. Its energy consumption is great, and its high $\mathrm{CO}_{2}$ emissions are obvious [36]. In the era of low-carbon economies, it is very urgent to achieve low carbon transformation in the Central Plains urban agglomeration.

According to the norms from the Intergovernmental Panel on Climate Change 
(IPCC), the administrative territorial scope for every city's $\mathrm{CO}_{2}$ emissions accounting should be considered in this paper. The emissions that occur in administered territories and offshore areas in which one region has jurisdiction are contained in administrative territorial emissions [37], which include the emissions generated by the socioeconomic sectors and residence activities directly within the region boundary [38]. The $\mathrm{CO}_{2}$ emissions inventory contains two parts, which are from fossil fuel consumption and industrial processes. The territorial scope for $\mathrm{CO}_{2}$ emissions accounting of every city here was made according to the IPCC guidelines (as shown in appendix table 1). Removing non-combustion energy consumption, such as energy loss, non-energy use and processing conversion, the $\mathrm{CO}_{2}$ emissions inventory of 17 fossil energy sources, 47 socioeconomic sectors and 9 industrial processes (appendix table 2, 3) were compiled according to Shan et al [34]. Due to Luohe's lack of energy-related data, the accounting of the $\mathrm{CO}_{2}$ emissions of the Central Plains urban agglomeration in the following only covers 29 cities (excluding Luohe in Henan).

\subsection{Emissions accounts}

The inventory of $\mathrm{CO}_{2}$ emissions is the basis for the establishment of climate models and the formulation of national emission reduction policies and international negotiations. Current national and global $\mathrm{CO}_{2}$ emissions are estimated based on IPCC methods and energy statistics data by international agencies. The parameters and methods of estimating $\mathrm{CO}_{2}$ emissions mainly come from the statistics of developed countries and may misestimate China's $\mathrm{CO}_{2}$ emissions. Based on the theory of matter conservation and the energy balance sheet, the CEADs team has developed a $\mathrm{CO}_{2}$ emission inventory model for multiple scales in China (national, provincial, and prefecture-level city) and adopted actual measured emission factors [39] which are more consistent with China's energy quality. Systematically compiling China's multi-scale $\mathrm{CO}_{2}$ emissions inventory can accurately measure regional $\mathrm{CO}_{2}$ emissions in order to analyse the characteristics of urban $\mathrm{CO}_{2}$ emissions in China. $\mathrm{CO}_{2}$ emission 
inventory model needs a number of relevant data, while not each city has the data needed.

In general, the accounting for $\mathrm{CO}_{2}$ emissions consists of the emissions from energy-related ( $\left.C E_{\text {energy }}\right)$ and industrial processes $\left(C E_{\text {process }}\right)$. According to the IPCC method [37], $\mathrm{CO}_{2}$ emissions are equal to the multipliers of the activity data (AD) and the emission factors of energy $(\mathrm{EF})$.

Formula 1 is used to calculate the $\mathrm{CO}_{2}$ emissions related to energy. $C E_{i j}$ denotes the $\mathrm{CO}_{2}$ emissions derived from the $\mathrm{i}$-th energy in sector $\mathrm{j} . A D_{i j}$ represents the consumption of the $\mathrm{i}$-th fossil fuel in sector $\mathrm{j}$, and $E F_{i}$ refers to the emission factors of the i-th energy.

$$
\begin{aligned}
C E_{\text {energy }}= & \sum_{j} \sum_{i} C E_{i j} \\
= & \sum_{j} \sum_{i}\left(A D_{i j} \times N C V_{i} \times E F_{i} \times O_{i j}\right) \\
& \quad \mathrm{i} \in[1,17], \mathrm{j} \in[1,47]
\end{aligned}
$$

where $\mathrm{i}$ indicates 17 kinds of energy (appendix table 2), and $\mathrm{j}$ manifests as 47 sectors (appendix table 3). The emissions factors of fossil fuel combustion are shown in appendix table 2 .

Formula 2 is used to estimate the $\mathrm{CO}_{2}$ emissions related to industrial processes. $C E_{t}$ is the $\mathrm{CO}_{2}$ emissions from the $\mathrm{t}$-th industrial process, $A D_{t}$ indicates the production of the t-th industrial process, $E F_{t}$ represents the corresponding emission factor, and $\mathrm{t}$ represents the industrial process in appendix table 4.

$$
C E_{\text {process }}=\sum_{t} C E_{t}=\sum_{t}\left(A D_{t} \times E F_{t}\right), \quad t \in[1,9]
$$


Accordingly, the activity data contain $A D_{i j}$ and $A D_{t}$. The energy balance table covers the total different kinds of fossil fuel consumption $\left(A D_{i}\right)$. Using the energy consumption data of different industries, the total amount can be divided into 47 sectors and $A D_{i j}$ can be obtained. Therefore, the core data needed to compile an emission inventory include the energy balance table (EBT) and the energy consumption data from different sectors in the industry (IS) and $A D_{t}$.

\subsection{Decoupling}

Decoupling theory is widely used to evaluate environmental resource use. There are some measurement methods to do decoupling include the comprehensive change analysis method, OECD decoupling index method, Tapio elastic analysis method, decoupling analysis method based on complete decomposition technology, IPAT model, descriptive statistical analysis method, econometric analysis, differential regression coefficient method and so on. Here, Tapio elastic analysis method is used to evaluate the decoupling relationship between $\mathrm{CO}_{2}$ emissions and GDP in the equation (3) [26]. As Tapio elastic analysis calculates the decoupling degree with the elasticity value of pressure variable and economic factor, which can make the decoupling index more flexible in time scale and make the final results analysis more comprehensive. The decoupling index $(\varepsilon)$ is utilized to describe the degree and direction of decoupling (as shown in equation (3)), which generally takes the changing value of GDP as the independent variable and views the changing value of energy consumption or $\mathrm{CO}_{2}$ emissions as the dependent variable. The shortcomings of the decoupling index is that it is an elastic value and it is difficult to explain the decoupling relationship between energy or $\mathrm{CO}_{2}$ emissions and economic growth by using a single decoupling index. Moreover, the decoupling model should adopt long-term data to calculate the decoupling index, which is not applicable to relative short-term data. Therefore, it needs to be interpreted with indicators such as energy 
intensity and carbon emission intensity together. In order to avoid the defect of such a single decoupling index to explain the relationship between $\mathrm{CO}_{2}$ emission and economic growth, this paper uses $\mathrm{CO}_{2}$ emission intensity and the decoupling index to explain the relationship together. Moreover, the decoupling model should adopt long-term data to calculate the decoupling index, which is not applicable to relative short-term data.

$$
\varepsilon=\frac{\Delta \mathrm{CO}_{2} / \mathrm{CO}_{2}}{\Delta G D P / \triangle G D P}
$$

The types of decoupling (as shown in table 2) are often divided into the connection (including recession connection and expansive connection), decoupling (including recession decoupling, strong decoupling and weak decoupling), and negative decoupling (including expansive negative decoupling, strong negative decoupling and weak negative decoupling).

\section{Table 2}

Decoupling indices and types

\begin{tabular}{|c|c|c|c|c|}
\hline \multicolumn{2}{|c|}{ Decoupling types } & ${ }^{\Delta} \mathrm{CO}_{2}$ & $\triangle G D P$ & $\varepsilon$ \\
\hline \multirow{2}{*}{ The connection } & Recession connection & $<0$ & $<0$ & $(0.8,1.2)$ \\
\hline & Expansive connection & $>0$ & $>0$ & $(0.8,1.2)$ \\
\hline \multirow{3}{*}{ Decoupling } & Recession decoupling & $<0$ & $<0$ & $(1.2,+\infty)$ \\
\hline & Strong decoupling & $<0$ & $>0$ & $(-\infty, 0)$ \\
\hline & Weak decoupling & $>0$ & $>0$ & $(0,0.8)$ \\
\hline \multirow{3}{*}{$\begin{array}{c}\text { Negative } \\
\text { decoupling }\end{array}$} & Expansive negative decoupling & $>0$ & $>0$ & $(1.2,+\infty)$ \\
\hline & Strong negative decoupling & $>0$ & $>0$ & $(-\infty, 0)$ \\
\hline & Weak negative decoupling & $<0$ & $<0$ & $(0,0.8)$ \\
\hline
\end{tabular}

(source: Sun [40]) 


\subsection{Uncertainty analysis}

There are many uncertain factors affecting the estimation of urban $\mathrm{CO}_{2}$ emissions, such as the impacts of basic data of energy consumption statistics and the activity level, the statistical methods, the numbers selection of emission factors in the calculation process, etc. This can have impacts on the estimation of $\mathrm{CO}_{2}$ emissions at the city level. Furthermore, it is difficult to obtain some data for activity levels directly, such as the amount of urban solid waste production. These are the differences with the actual situation of the cities, which will affect the reliability of the calculation results [41]. The Monte Carlo analysis can address a wide range of uncertainties, which can be combined uncertainties with any probability distribution range. The uncertainties analysis offers intervals with lower and upper bounds of a certain confidence interval (CI) around the estimates. The Monte Carlo analysis is set up with the input parameters of activity data and emission factors. The activity data and emission factors are presumed to be normally distributed. The coefficients of variations $(\mathrm{CV}$, standard deviation divided by the mean) are from previous research $[34,42]$. According to the Monte Carlo analysis, the main steps are (1) determining the probability distribution of the activity level in different sectors, emission factors and other estimation parameters; (2) calculating the $\mathrm{CO}_{2}$ emissions; and (3) simulating again and again to obtain the probability distribution of $\mathrm{CO}_{2}$ emissions [43]. The simulation procedures are repeated 20,000 times in the Monte Carlo analysis. After the simulation, the uncertainty analysis for the $\mathrm{CO}_{2}$ emissions in 29 cities ranged from $-5.8 \%$ to $3.9 \%$.

\subsection{Data source}

The latest available data from 2000 to 2015 were collected from the cities' statistical yearbook, and all of the data used and the results were uploaded to CEADs.net and supporting information for free academic use. The indicators cover 
GDP (the primary, secondary and tertiary industries), the population of prefecture-level cities and provinces (urban population and rural population), the output of industrial products, $\mathrm{AD}_{\mathrm{ij}}$, the total industrial output value above a designated scale and the total industrial output value. When the statistical yearbooks of the 29 cities had available data, they were utilized directly in the calculation. If not, they were handled according to the methods from Shan et al. [34]. The GDP data here were standardized to the currency values for the year 2000, which are the constant GDP data. Constant GDP is equal to the data of the current GDP value divided by the GDP deflator.

\section{Results and discussion}

\subsection{Characteristics of $\mathrm{CO}_{2}$ emissions in 29 cities}

From the total $\mathrm{CO}_{2}$ emissions according to the different trends of $\mathrm{CO}_{2}$ emissions from 2000 to 2015 , the 29 cities are roughly divided into 4 categories. From the results, the $\mathrm{CO}_{2}$ emissions trends of 7 cities appeared to have abrupt fluctuations, and 9 cities trended steadily upward. The $\mathrm{CO}_{2}$ emissions in 10 cities increased initially and then decreased, and the emissions were relatively stable in 3 cities (Appendix figure 1). From appendix figure 1, of the 7 cities with the trend of abrupt fluctuation, Handan had the highest $\mathrm{CO}_{2}$ emissions in each year, and the gap with the other 6 cities grew larger year after year. In the 9 cities with the steady upward trend, Shangqiu had the highest $\mathrm{CO}_{2}$ emissions from 2004 to 2010 due to its higher coal consumption than the other 8 cities. There were trends of initially increasing and then decreasing $\mathrm{CO}_{2}$ emissions in 10 cities. The $\mathrm{CO}_{2}$ emissions of Pingdingshan and Changzhi were higher than those of the other cities in the same year. In the 3 cities with a trend of relative stability, the $\mathrm{CO}_{2}$ emissions showed a steady tendency as a whole, as they had a very stable industrial structure, energy consumption and urbanization rate over that period.

The emission intensity indicates the amount of $\mathrm{CO}_{2}$ emissions emitted per capita 
GDP. It is mainly used to measure the relationship between the urban economy and $\mathrm{CO}_{2}$ emissions. For the 7 cities with the trend of abrupt fluctuation, except for an individual year, the emission intensity of Handan, Zhoukou and Zhumadian had roughly downward trends. The $\mathrm{CO}_{2}$ emission intensity trends of the other 4 cities were the same as the trend of their $\mathrm{CO}_{2}$ emissions, showing an unsteady trend of alternate declines and increases. For the 9 cities with the steady upward trend, the changes in the emission intensity of Kaifeng, Handan, Suzhou, Liaocheng, and Heze were all relatively stable within the period, indicating that the changes in $\mathrm{CO}_{2}$ emissions were synchronized with the changes in their GDP. For the 10 cities with the trend of increasing initially and then decreasing, the emission intensity in Changzhi, Pingdingshan, and Xingtai were relatively higher between 2000 and 2015. For the 3 cities with the trend of relative stability, the emission intensity basically fell in the period, indicating that emission reduction policies were useful in 3 cities.

As seen from the per capita $\mathrm{CO}_{2}$ emissions (appendix figure 3), in the 7 cities with the trend of abrupt fluctuation, the per capita $\mathrm{CO}_{2}$ emissions in Anyang, Handan and Yuncheng had not changed much mainly because their ratios of $\mathrm{CO}_{2}$ emissions to population had not changed significantly. In the 9 cities with the steady upward trend, the per capita $\mathrm{CO}_{2}$ emissions in Jiyuan were relatively larger and trended upward, possibly relating to its small population. In the 10 cities with the trend of increasing initially and then decreasing, similar to Pingdingshan, Luoyang also achieved its highest point in 2011. It can also be considered to have peaked. In the 3 cities with the trend of relative stability, the change trends of the per capita $\mathrm{CO}_{2}$ emissions appeared steady. The per capita $\mathrm{CO}_{2}$ emissions in Fuyang remained basically unchanged.

\section{2 $\mathrm{CO}_{2}$ emissions by energy types, industrial process and different sectors in 2015}

The total emissions are divided into coal-related, oil-related, gas-related, and process-related emissions in figure 1. This paper uses the more complete and latest 
data in 2015 to explore the $\mathrm{CO}_{2}$ emissions from three kinds of energy and industrial processes. As some cities did not have energy consumption data in 2015, this paper estimated their $\mathrm{CO}_{2}$ emissions in 2015 according to the data in prior years. The ratios from coal consumption accounting for the total $\mathrm{CO}_{2}$ emissions in 29 cities were clearly bigger than from other energy types and industrial processes, and they ranged from $52.3 \%$ in Puyang to $98.51 \%$ in Changzhi, the latter being a typical coal-based city. For oil consumption, the ratios accounting for the total $\mathrm{CO}_{2}$ emissions ranged from $0.76 \%$ in Changzhi to $3 \%$ in Puyang. As Puyang owns the Central Plains oil field, the ratio was relatively higher there than for other cities. With regards to gas consumption, the ratios ranged from $0.19 \%$ in Anyang to $13.72 \%$ in Puyang, which was also because Puyang controls the Central Plains oil field. The ratios from industrial processes accounting for the total $\mathrm{CO}_{2}$ emissions in 29 cities ranged from $0.51 \%$ in Changzhi to $17.92 \%$ in Zhumadian.

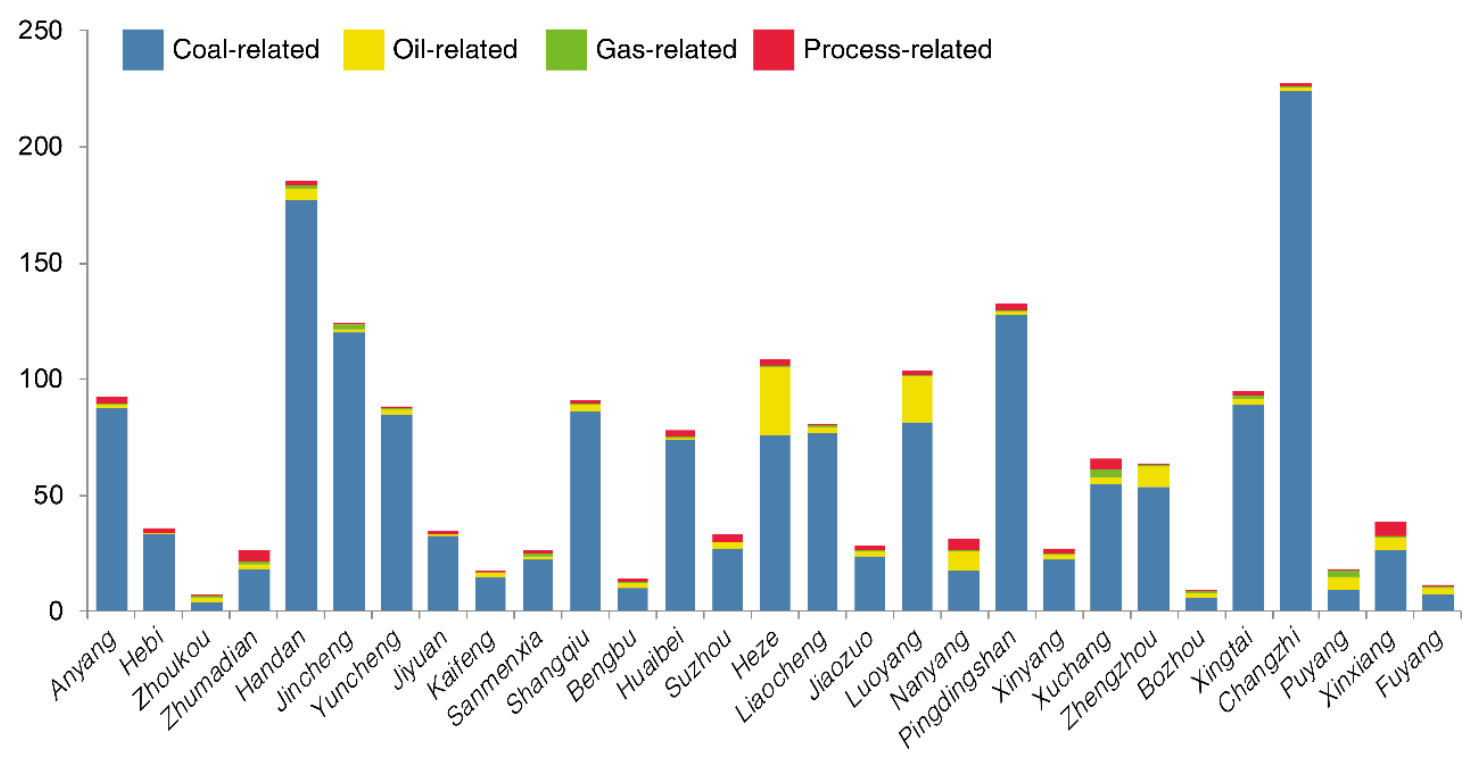

Fig. 1. $\mathrm{CO}_{2}$ emissions from different kinds of energy and industrial processes in 2015 (Mt)

The $\mathrm{CO}_{2}$ emissions produced by different sectors in the 29 cities were significantly different in 2015 (figure 2). To analyse the effects of the development of some key industries on $\mathrm{CO}_{2}$ emissions, this paper merged 45 sectors into 9 sectors. The ratios of $\mathrm{CO}_{2}$ emissions from the coal mining industry accounting for the total 
emissions ranged from $0 \%$ in 12 cities to $81 \%$ in Huaibei. For petroleum processing and coking, the ratio in Yuncheng was the largest (40\%). In the production and supply of electric power, steam and hot water, the ratios were bigger than other sectors in most cities, and the biggest ratio was $56 \%$ in Liaocheng. Regarding transportation, storage, post and telecommunication services, Zhengzhou had the largest ratio of $\mathrm{CO}_{2}$ emissions of the 29 cities. Because Zhengzhou is the only core city in the Central Plains urban agglomeration, it experiences heavy traffic.

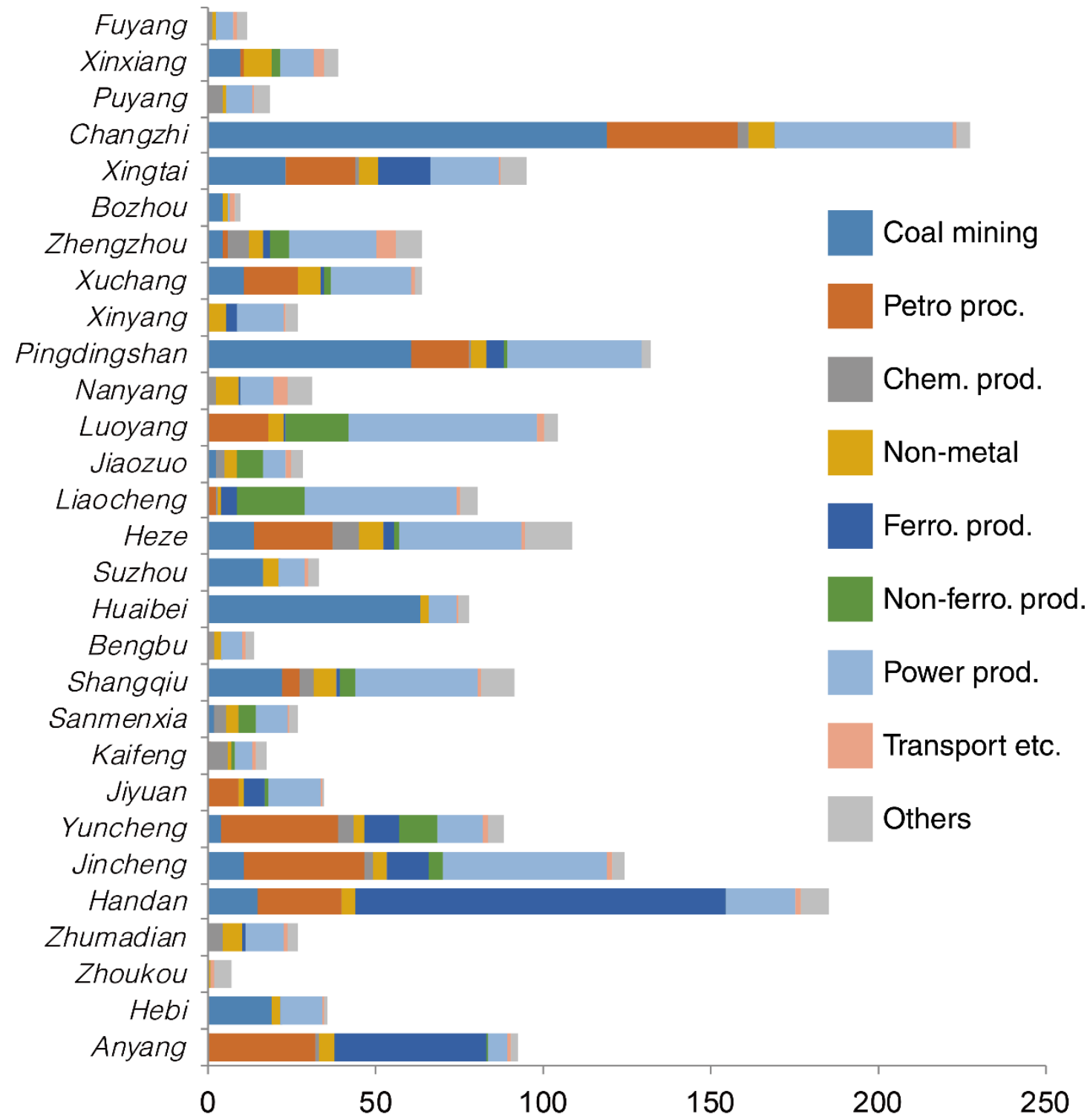

Fig. 2. $\mathrm{CO}_{2}$ emissions produced by different sectors in 2015 (Mt).

Notes: Coal mining and Dressing (Coal mining), Petroleum Processing and Coking (Petroleum proc.), Raw Chemical Materials and Chemical Products (Chemical prod.), Nonmetal Mineral 
Products (Non-metal), Smelting and Pressing of Ferrous Metals (Ferro prod.), Smelting and Pressing of Nonferrous Metals (Non-ferro prod.), Production and Supply of Electric Power, Steam and Hot Water (Power prod.), Transportation, Storage, Post and Telecommunication Services (Transport etc.), Other Industries (Others)

\subsection{Decoupling analysis between GDP and $\mathrm{CO}_{2}$ emissions}

For the period from 2000 to 2015, the decoupling analysis between GDP and $\mathrm{CO}_{2}$ emissions in 29 cities is shown in figure 3. In 13 cities including Anyang, Zhumadian, Handan, Kaifeng, Sanmenxia, Luoyang, Nanyang, Pingdingshan, Xinyang, Xuchang, Zhengzhou, Puyang and Xinxiang a weak decoupling appeared between GDP and $\mathrm{CO}_{2}$ emissions, indicating that the $\mathrm{CO}_{2}$ emissions increased with the GDP while the change rate of $\mathrm{CO}_{2}$ emissions appeared slower than that of GDP. Five cities (Zhoukou, Yuncheng, Jiaozuo, Xingtai and Fuyang) experienced a weak decoupling to strong decoupling after 2010, which was the end of the golden decade for the coal industry; the change rate of $\mathrm{CO}_{2}$ emissions appeared slower than that GDP, and $\mathrm{CO}_{2}$ emissions decreased, creating the ideal state for low-carbon cities. Seven cities, including Hebi, Jincheng, Shangqiu, Bengbu, Suzhou, Heze and Bozhou, showed expansive negative decoupling, meaning that the $\mathrm{CO}_{2}$ emissions increased with the GDP while the change rate of $\mathrm{CO}_{2}$ emissions was faster than that of GDP. Four cities, including Jiyuan, Changzhi, Huaibei and Liaocheng, showed expansive connection, indicating that the change rates of $\mathrm{CO}_{2}$ emissions and GDP appeared synchronous with growth, which was not an ideal development state. 


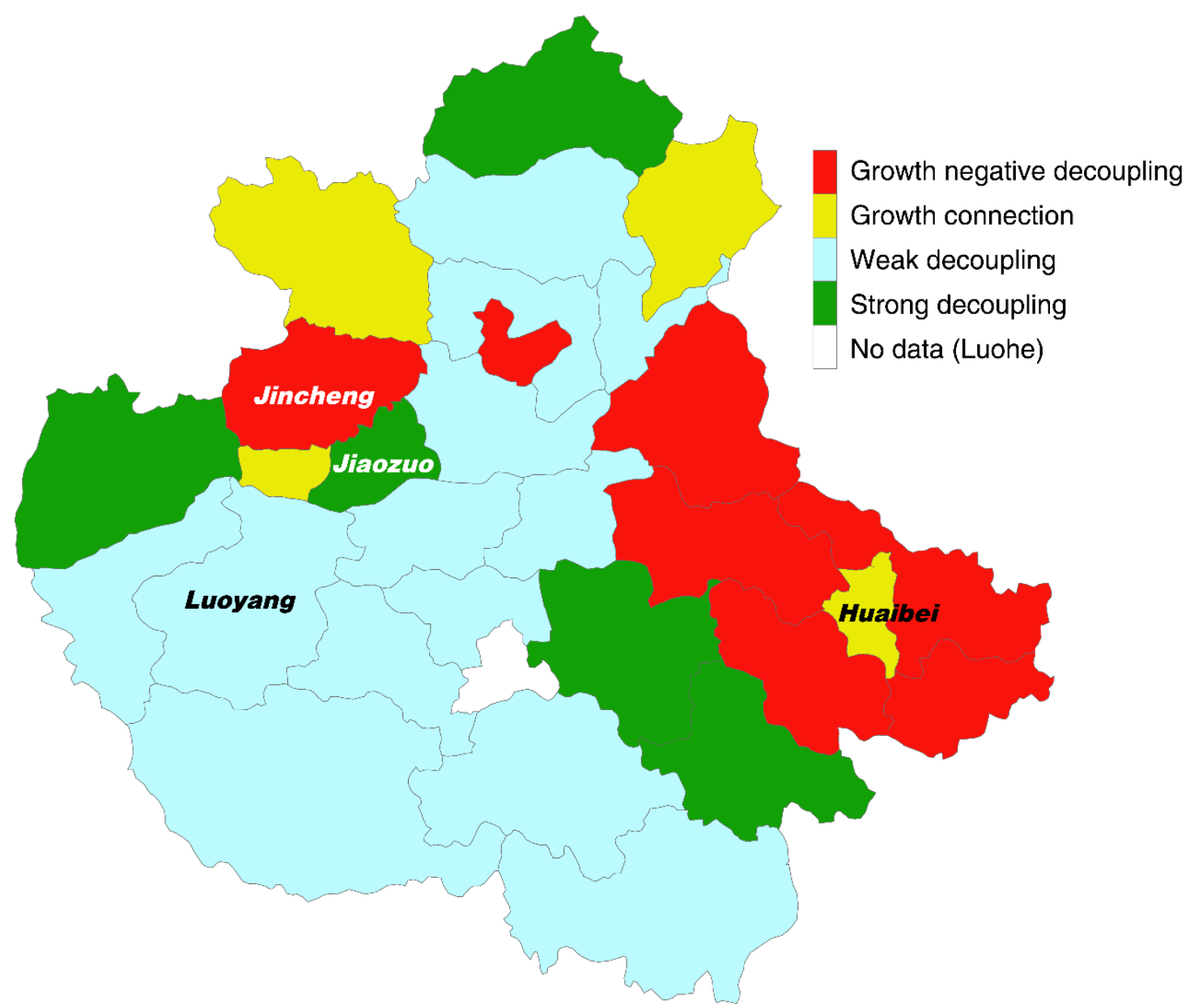

Fig. 3. Decoupling analysis between GDP and $\mathrm{CO}_{2}$ emissions in 29 cities from 2000 to 2015

To analyse the low-carbon development paths in different types of cities in more detail, this paper selected four typical cities as cases to analyse four different decoupling states (figure 4). 

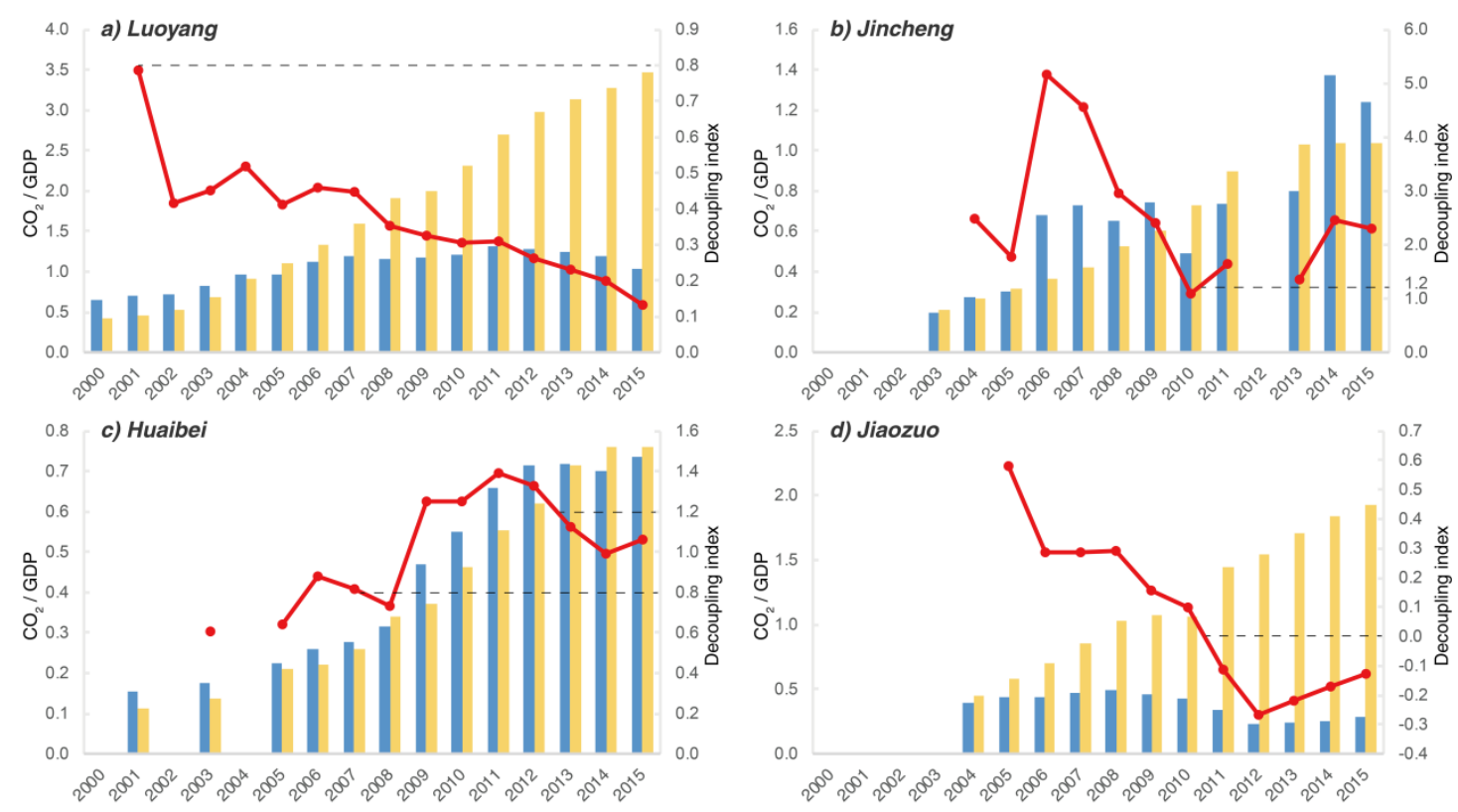

Fig. 4. GDP, $\mathrm{CO}_{2}$ emissions and decoupling index in 4 cities from 2000 to 2015

\section{(1) Expansive negative decoupling cities}

Expansive negative decoupling means that the $\mathrm{CO}_{2}$ emissions increase with the GDP, and the $\mathrm{CO}_{2}$ emissions grow faster than the GDP. Jincheng, Shangqiu and Hebi are coal resource cities that have the energy structure of typical highly carbonized cities, which is the most important factor for the rapid growth of $\mathrm{CO}_{2}$ emissions. Heze, Bozhou, Suzhou and Bengbu are all four cities in northern Anhui and western Shandong in the early or middle stage of industrialization and that selected the extensive development road of "pollution first, treatment afterwards". Economic growth is characterized as high input, high energy consumption and high emissions. At the same time, they may also be affected by the measures to stimulate economic development. These cities implemented the industrial agglomeration development strategy and increased the investment and production of high-energy projects, leading to a large increase in energy consumption and $\mathrm{CO}_{2}$ emissions.

Taking Jincheng as an example to discuss expansive negative decoupling (figure 4a). The $\mathrm{CO}_{2}$ emissions in Jincheng increased with an annual growth of as high as 
15.3\%. However, they appeared in a mixed state. Although Jincheng issued its low-carbon development plan in 2014 to require industrial restructuring, energy restructuring and carbon reduction projects in key areas [44], its higher urbanization rate and higher ratio of secondary industry accounting for the three industries still had important impacts on increasing $\mathrm{CO}_{2}$ emissions, and the highest ratio was $65.5 \%$ in 2011. The emission intensity in Jincheng also presented an unstable state. The total $\mathrm{CO}_{2}$ emissions in Jincheng were not the highest, but due to its smaller population its per capita $\mathrm{CO}_{2}$ emissions were the largest compared with the other cities in the same year. Subsequently, it fell slightly to 56.65 tons/per capita in 2015 . The $\mathrm{CO}_{2}$ emissions from coal consumption accounted for the highest proportion in Jincheng (as high as $96.64 \%$ ) in 2015 , and they were related to the coal resources-based background of the city. As for petroleum processing and coking, the proportion of $\mathrm{CO}_{2}$ emissions from petroleum processing and coking was $29 \%$, indicating that close attention needs to be paid to petroleum processing and coking for emissions reduction. The production and supply of electric power, steam and hot water in Jincheng had a higher ratio of $\mathrm{CO}_{2}$ emissions.

\section{(2) Expansive connection cities}

Expansive connection means that when the economy is growing, energy consumption and $\mathrm{CO}_{2}$ emissions increase at the same time; this is not an ideal state. The economic growth pattern changes from extensive expansion to intensive development, but the change of economic growth mode can only gradually reduce a small part of the $\mathrm{CO}_{2}$ emissions. The economic growth has not eliminated the growth of energy consumption and $\mathrm{CO}_{2}$ emissions, and it has not achieved the transition to a decoupling state.

Here, Huaibei is utilized to analyse the expansive connection state (figure 4b). The $\mathrm{CO}_{2}$ emissions were higher than in the other 8 cities (except Shangqiu, without data) in its group after 2010. As an old coal-based industrial city, Huaibei has a 
relatively higher per capita GDP, one of the highest ratios of coal consumption in the energy structure (accounting for more than $94 \%$ of $\mathrm{CO}_{2}$ emissions), and a higher ratio of secondary industry in the industry structure (basically more than 60\%) than the other 8 cities. With the transformation of the non-coal industry in Huaibei, $\mathrm{CO}_{2}$ emissions will decrease in the future. The emission intensity of Huaibei was bigger than that of the other 8 cities, which varied between 11.38 to 17.16 tons per ten thousand yuan. When the $\mathrm{CO}_{2}$ emissions in Huaibei were similar to those in some other cities, the emission intensity was relatively larger due to its relatively smaller GDP, the same as Jiyuan. The per capita $\mathrm{CO}_{2}$ emissions in Huaibei generally increased from 7.76 to 33.83 tons per capita in 2001-2015, and the overall trend was upward except for a slight declining in some years. That is mainly because of its relatively larger $\mathrm{CO}_{2}$ emissions and lower population. The highest proportions of $\mathrm{CO}_{2}$ emissions from coal consumption accounted for more than 94\%. Huaibei is a coal-based city, and coal plays an important role in the local economy. The coal industry is still in transition while the local service industry has not yet formed. Huaibei has issued a low-carbon city pilot action plan (2017-2020), and it was successfully selected for the third batch of national pilot low-carbon cities [45], laying the foundation for achieving low-carbon development. Huaibei can transform its single coal mining industry into a coal, electricity, coke, chemical, and building materials industry, including the whole industrial chain development pattern in the future.

\section{(3) Weak decoupling analysis}

Weak decoupling means that economic growth changes from relying on the increase in energy consumption to the improvement of its use efficiency, and the influence of energy consumption on economic growth gradually weakens. When this influence weakens to a certain extent, economic growth can be decoupled from $\mathrm{CO}_{2}$ emissions. It may be because powerful measures have been taken to constantly 
optimize the industrial structure and eliminate and close a number of enterprises with low production efficiency and high energy consumption, which improve the efficiency of energy utilization. However, as the impact of energy consumption on economic growth is limited, 13 cities presented a weak decoupling state.

Luoyang was selected as a case to analyse weak decoupling (figure 4c). The $\mathrm{CO}_{2}$ emissions and per capita $\mathrm{CO}_{2}$ emissions of Luoyang both peaked in 2011 and showed a downward trend after. The emission intensity in Luoyang showed roughly declining trends. It was remarkable in the characteristics of $\mathrm{CO}_{2}$ emissions driven by industries. The industrial structure was mainly based on heavy industry and high energy consumption industries. The $\mathrm{CO}_{2}$ emissions from the high material consumption and high energy consumption industries such as Production and Supply of Electric Power, Steam and Hot Water, Smelting and Pressing of Nonferrous Metals and Petroleum Processing and Coking accounted for $90 \%$ of the total emissions. Economic growth belonged to the "high carbon" type. Luoyang launched the China-Europe low-carbon eco-city cooperation project in 2015 [46] which provides a reference for the construction of low-carbon cities by learning from the experience of the green and low-carbon development of European cities.

\section{(4) Strong decoupling analysis}

Strong decoupling shows that economic growth has shifted from relying on increasing energy consumption to more efficient use of energy and strict implementation of policies. The economic growth has eliminated the dependence on energy consumption and $\mathrm{CO}_{2}$ emissions growth, and energy consumption has greatly reduced its influence on economic growth. At this time, energy consumption and $\mathrm{CO}_{2}$ emissions have both decreased, achieving an ideal state of less energy consumption and more economic growth.

Jiaozuo is a typical strong decoupling city (figure 4d), and it reached an ideal low-carbon development state in 2010 , which was the end of the golden decade for 
the coal industry. It can be deduced that Jiaozuo has reached a low-carbon path. Jiaozuo is a coal-resource-based city, and secondary industry accounted for a large proportion of $\mathrm{CO}_{2}$ emissions. Jiaozuo produced more coal resources, which had a greater influence on $\mathrm{CO}_{2}$ emissions. The added values in the resource-based industrial enterprises accounted for more than three-quarters of the city's industrial added values at one time. However, with the exhaustion of coal resources and the simplification of the industrial structure, the average annual growth rate in Jiaozuo was only $3.5 \%$ during the Ninth Five-year Plan. In March 2008, with the approval of the State Council, Jiaozuo was listed as one of the first 12 resource-depleted cities in China as a representative of a typical resource-depleted city in central China, which brought many opportunities for sustainable development [47]. Since then, Jiaozuo has successfully weathered the economic recession and dependence on coal resources, and it has achieved GDP growth and the reduction of $\mathrm{CO}_{2}$ emissions.

\section{Conclusions}

This paper estimates the $\mathrm{CO}_{2}$ emissions, emission intensity, and per capita $\mathrm{CO}_{2}$ emissions and discusses the decoupling states in 29 cities from 2000 to 2015 . The paper offers data base for $\mathrm{CO}_{2}$ emissions accounting, emission reduction and low-carbon paths. Each city can make $\mathrm{CO}_{2}$ emission standard policies according to its GDP, energy consumption structure, industrial structure, urbanization process and other aspects [48, 49]. The main conclusions are as follows.

There are large differences in the total $\mathrm{CO}_{2}$ emissions and the shares of various sectors in different cities. On the whole, the $\mathrm{CO}_{2}$ emissions and emission intensity in the north western part are relatively larger than in the southeast, and the overall low carbon level is relatively lower. We therefore conclude that the $\mathrm{CO}_{2}$ emissions, emission intensity and per capita $\mathrm{CO}_{2}$ emissions in coal-based cities, heavy industry cities and cities with smaller populations were relatively higher while the $\mathrm{CO}_{2}$ emissions, emission intensity and per capita $\mathrm{CO}_{2}$ emissions were relatively lower in 
more agricultural, less developed and more populous cities. Examining different kinds of energy and industrial processes, the $\mathrm{CO}_{2}$ emissions from coal consumption accounted for a majority of the total emissions (more than 50\%), which are the same with Guangdong-Hong Kong-Macao Greater Bay Area cities [50]. The proportion of $\mathrm{CO}_{2}$ emissions from coal consumption even exceeded $94 \%$ in some coal-based cities and industrial cities such as Anyang, Handan, Jincheng, Yuncheng, Shangqiu, Huaibei, Pingdingshan, and Changzhi. The $\mathrm{CO}_{2}$ emissions from gas were lower in all 29 cities. We therefore conclude that the industrial structure and energy consumption structure of these cities were mainly based on coal resources and relatively slower in evolution. The industrial structure, energy structure and $\mathrm{CO}_{2}$ emissions had significant correlation characteristics, which meant the $\mathrm{CO}_{2}$ emissions growth rate did not significantly slow down. Seen from different sectors, the $\mathrm{CO}_{2}$ emissions reduction potential was great, but the $\mathrm{CO}_{2}$ emissions reduction was also difficult. $\mathrm{CO}_{2}$ emissions from production and supply of electric power, steam and hot water, coal mining and dressing were higher, which are consistent with those from 18 central Chinese cities [51]. When it comes to decoupling, only 5 cities (Zhoukou, Yuncheng, Jiaozuo, Xingtai and Fuyang) showed strong decoupling since 2010, reaching the ideal low-carbon development state. It can be deduced that the relatively smaller proportion of industrial structures in Zhoukou and Puyang and the end of the golden decade for the coal industry made Yuncheng, Jiaozuo and Xingtai reach their low-carbon paths. For the 13 cities that had weak decoupling and the other 11 cities, strong decoupling has been limited because the change rate of $\mathrm{CO}_{2}$ emissions appears much slower than that of GDP. The decoupling between $\mathrm{CO}_{2}$ emissions and GDP in 29 cites can provide data base for the realization of decoupling and low-carbon paths in 29 cities. After understanding the decoupling status of each city, the government can take concrete measures to help each city to achieve the decoupling of $\mathrm{CO}_{2}$ emissions and GDP as soon as possible. 
For the low-carbon paths of the cities, the paper proposes that the proportion of coal purification to achieve low carbon energy should be increased firstly. The current energy structure in the Central Plains urban agglomeration is mainly based on coal resources. The proportion of coal accounting for the current energy structure in some cities is higher than the national average. Therefore, it is difficult to significantly reduce the proportion of coal in the short term. Vigorously developing coal purification technologies is a practical strategy for construction in low-carbon cities in the Central Plains urban agglomeration. Then, the energy consumption structure should be changed. The energy consumption structure can be shifted from the traditional coal consumption structure to coal, oil and gas. These 29 cities can well utilize the "West-East Gas Transmission" project to guide them to restructure their energy consumption structure. Meanwhile, the cities can actively develop and utilize new and clean energy resources according to their development plans. Lastly, economic means can be used to control $\mathrm{CO}_{2}$ emissions. Economic instruments include $\mathrm{CO}_{2}$ emissions trading rights and taxes. The establishment and start-up of the carbon market will affect the production of some industries and also the economic development of the cities to a certain extent, which is conducive to reducing emissions.

\section{Acknowledgements}

All the data can be download freely from China Emission Accounts and Datasets (CEADs) at http://www.ceads.net. The authors express their sincere thanks for the support from the National Natural Science Foundation of China under Grant No. 71803182 and 71773118, Beijing Publicity Culture High-level Talent Training Subsidy Program under Grant No. 2017XCB031, Open Fund of State Key Laboratory of Water Resource Protection and Utilization in Coal Mining under Grant No. SHJT-17-42.20, the Fundamental Research Funds for the Central Universities under Grant No. 53200759032, Teaching Research and Teaching Reform Project Funds of 
China University of Geosciences (Beijing) in 2017 under Grant No. JGYB201715.

\section{Reference}

[1] Guan DB, Liu Z, Geng Y, Lindner S, Hubacek K. The gigatonne gap in China's carbon dioxide inventories. Nature Clim. Change 2012; 2(9), 672.

[2] The State Council. Tackling climate change: China has actively promoted actions and made great contributions. 2009.

http://www.gov.cn/jrzg/2009-12/17/content_1489577.htm (2009-12-17)

[3] Central People's Government of the People's Republic of China. Notice on the pilot work of low-carbon provinces and cities in National Development and Reform Commission.2010.

http://www.gov.cn/zwgk/2010-08/10/content_1675733.htm (2010-08-10)

[4] People Website. China's $\mathrm{CO}_{2}$ emissions peaked in 2030 and the US commits to reduce $\mathrm{CO}_{2}$ emissions. 2014.

http://politics.people.com.cn/n/2014/1113/c70731-26012421.html (2014-11-13)

[5] Phoenix News. China pledges to reach its $\mathrm{CO} 2$ emissions peak around 2030. http://news.ifeng.com/a/20151201/46471205_0.shtml (2015-12-01)

[6] Le Quéré et al.Global Carbon Budget 2017. 2017. http://www.globalcarbonproject.org/carbonbudget/17/files/GCP_CarbonBudget_2017.pdf

[7] National Bureau of Statistics of the People's Republic of China. Domestic demand has propped up China's economic growth. 2018.

http://www.stats.gov.cn/tjsj/sjjd/201804/t20180410_1592995.html (2018-04-10)

[8] The United Nations Human Settlements Programme. Cities and climate change: Global Human Settlements Report in 2011. Washington, 2011.

[9] Gu CL, Tan ZB, Liu W, Yu TF, Han Q, Liu HL, Dai YX, Liu ZL, Zheng SQ. Research progress on climate change, $\mathrm{CO}_{2}$ emissions and low-carbon urban planning. Urban planning forum, 2009, 3: 38-45.

[10] Zhang Y. Urbanization will be the main source of China's future $\mathrm{CO}_{2}$ emission growth. http://news.china.com.cn/txt/2015-06/17/content_35847226.htm (2015-06-17)

[11] Shan YL, Liu JH, Liu Z, Xu XWH, Shao S, Wang P, Guan DB. New provincial $\mathrm{CO}_{2}$ emission inventories in China based on apparent energy consumption data and updated emission 
factors. Appl. Energy 2016a; 184, 742-750.

[12] Shan YL, Guan DB, Zheng HR, Ou JM, Li Y, Meng J, Mi ZF, Liu Z, Zhang Q. China $\mathrm{CO}_{2}$ emission accounts 1997-2015. Sci Data 2017; DOI: 10.1038/sdata.2017.201.

[13] Mi ZF, Zhang YK, Guan DB, Shan YL, Liu Z, Cong RG, Yuan XC, Wei YM. Consumption-based emission accounting for Chinese cities. Appl. Energy 2016; 184, 1073-1081.

[14] Mi ZF, Wei YM, Wang B, Meng J, Liu Z, Shan YL, Liu JR, Guan DB. Socioeconomic impact assessment of China's $\mathrm{CO}_{2}$ emissions peak prior to 2030. J Clean Prod. 2017; 142: 2227-2236.

[15] Mi ZF, Meng J, Guan DB, Shan YL, Song ML, Wei YM, Liu Z, Hubacek K. Chinese $\mathrm{CO}_{2}$ emission flows have reversed since the global financial crisis. Nat commun 2017; 8(1): 1712.

[16] Meng J, Mi ZF, Guan DB, Li JS, Tao S, Li Y, Feng KS, Liu JF, Liu Z, Wang XJ, Zhang Q, Davis S. The rise of South-South trade and its effect on global $\mathrm{CO}_{2}$ emissions. Nat commun 2018; 9: 1871.

[17] Shan YL, Liu Z, Guan DB. $\mathrm{CO}_{2}$ emissions from China's lime industry. Appl. Energy 2016; 166: $245-252$.

[18] Ramaswami A, Tong K, Fang A, Lal RM, Nagpure AS, Li Y, Yu HJ, Jiang DQ, Russell A.G., Shi L, Chertow M, Wang YJ, Wang SX. Urban cross-sector actions for carbon mitigation with local health co-benefits in China. Nat. Clim. Change 2017; 7(10):736.

[19] Li JS, Zhou HW, Meng J, Yang Q, Chen B, Zhang YY. Carbon emissions and their drivers for a typical urban economy from multiple perspectives: A case analysis for Beijing city. Appl. Energ. 2018; 226: 1076-1086.

[20] Shan YL, Guan DB, Hubacek K, Zheng B, Davis SJ, Jia LC, Liu JH, Liu Z, Fromer N, Mi ZF, Meng J, Deng XZ, Li Y, Lin JT, Schroeder H, Weisz H, Schellnhuber HJ. City-level climate change mitigation in China. Sci. Adv. 2018; 4(6): eaaq0390.

[21] OECD. Indicators to measure decoupling of environmental pressure from economic growth. Sustainable development SG/SD 2002, 1(2002).

[22] OECD. Decoupling: A Conceptual Overview. OECD Publishing, 2006.

[23] Vehmas J, Kaivo-oja J, Luukkanen J. Global trends of linking environmental stress and economic growth. Turku: Finland Futures Research Centre 2003, 6.

[24] Shuai C, Chen X, Wu Y, Zhang Y, Tan YT. A three-step strategy for decoupling economic growth from carbon emission: Empirical evidences from 133 countries. Sci. Tot. Environ., 2019, 646: 524-543. 
[25] Juknys R, Miškinis V, Dagiliūtè R. New Eastern EU Member States: Decoupling of Environmental Impact from Fast Economy Growth. Environ. Res., Eng \& Mgt. 2005, 34(4): 68-76.

[26] Tapio P. Towards a theory of decoupling: degrees of decoupling in the EU and the case of road traffic in Finland between 1970 and 2001. Transport Pol. 2005, 12(2): 137-151.

[27] Enevoldsen M K, Ryelund A V, Andersen M S. Decoupling of industrial energy consumption and $\mathrm{CO}_{2}$-emissions in energy-intensive industries in Scandinavia. Energ. econ. 2007, 29(4): 665-692.

[28] Profillidis V, Botzoris G, Galanis A. Decoupling of economic activity from transport-related energy consumption: an analysis for European Union member countries. Int. J. Inno. Sust. Dev. 2018, 12(3): 271-286.

[29] Halicioglu F, Ketenci N. Output, Renewable and Non-renewable Energy Production, and International Trade: Evidence from EU-15 Countries. Energ, 2018, 159: 995-1002.

[30] Wang Z, Yang L. Delinking indicators on regional industry development and carbon emissions: Beijing-Tianjin-Hebei economic band case. Ecological indicators, 2015, 48: $41-48$.

[31] Xia Y, Zhong MC. The relationship between economic development and environmental pollution decoupling theory and EKC hypothesis-on the decoupling of China's prefecture-level cities.China Population Resources and Environment, 2016, 26(10): 8-16.

[32] Qi J, Chen B. Decoupling analysis of the cities' industries. China Population Resources and Environment, 2012, 8: 102-106.

[33] Wu D, Yuan C, Liu H. The decoupling states of $\mathrm{CO}_{2}$ emissions in the Chinese transport sector from 1994 to 2012: A perspective on fuel types. Energy \& Environment, 2018: $0958305 \times 18756669$.

[34] Shan YL, Guan DB, Zheng HR, Ou JM, Li Y, Meng J. China $\mathrm{CO}_{2}$ emission accounts 1997-2015. Sci. data 2018; 5: 170201.

[35] Shan YL, Guan DB, Liu JH, Mi ZF, Liu Z, Liu JR, Schroeder H, Cai BF, Chen Y, Shao S, Zhang Q. Methodology and applications of city level $\mathrm{CO}_{2}$ emission accounts in China. J Clean Prod 2017; 161: 1215-1225.

[36] National Development and Reform Commission of the People's Republic of China. The state development and reform commission issued a circular on the development planning of the central plains urban agglomeration. 2016.

http://www.ndrc.gov.cn/zcfb/zcfbtz/201701/t20170105_834444.html (2016-12-29)

[37] Rong PJ. Effects on urbanization development and $\mathrm{CO}_{2}$ emission in Henan. J Henan 
University (Natural Science) 2016; 46 (5): 514-521.

[38] IPCC. IPCC Guidelines for national greenhouse gas inventories. Institute for Global Environmental Strategies, 2006.

[39] Barrett J, Peters G, Wiedmann T, Scott K, Lenzen M, Roelich K, Qu é r é CL. Consumption-based GHG emission accounting: a UK case study. Clim. Pol. 2013, 13: 451-470.

[40] Liu Z, Guan DB, Wei W, Steven JD, Philippe C, Bai J, Peng S, Zhang Q, Hubacek K, Marland G, Andres RJ, Brown DC, Lin JT, Zhao HY, Hong CP, Boden TA, Feng KS, Peters GP, Xi FM, Liu JG, Li Y, Zhao Y, Zeng N, He KB. Reduced carbon emission estimates from fossil fuel combustion and cement production in China. Nat. 2015: 524(7565): 335-338.

[40] Sun R. Improving tapio decoupling measurement method and its applications. Tec. Econ. Mgt Res. 2014, 8: 7-11.

[41] Winiwarter W, Muik B. Statistical dependence in input data of national greenhouse gas inventories: effects on the overall inventory uncertainty. Springer, Dordrecht 2010: 19-36.

[42] Zhao Y, Nielsen CP, Lei Y, McElroy MB, Hao J. Quantifying the uncertainties of a bottom-up emission inventory of anthropogenic atmospheric pollutants in China. Atmos. Chem. Phys. 2011, 11: 2295-2308.

[43] Zhang XM, Zhuang GY, Liu J. Uncertainty Analysis of Urban Greenhouse Gas Inventories. Environ. Econ. Research. 2018, 3(1):8-18.

[44] The People's Government of Jincheng City. The People's Government of Jincheng City issued a notice on the low-carbon development plan of Jincheng City (2013-2020) http://www.jchb.gov.cn/szffffw/26683.jhtml (2014-07-18)

[45] Huaibei Municipal Commission of Development and Reform. Set up and bear in mind the concept of green development to create green gold model cities.

http://fgw.huaibei.gov.cn/content/detail/5a406074a6039c250e047e6e.html (2017-06-12) http://www.pdszx.gov.cn/pdszx-n-1513.html (2015-06-09)

[46] Luoyang People's Government. Luoyang was selected as one of the comprehensive pilot cities of China-Europe the low-carbon eco-city cooperation project.

https://www.henan.gov.cn/2015/04-02/564405.html (2015-04-03)

[47] The Central People's Government of the People's Republic of China, 2008. Research on the sustainable development of the first 12 resource-exhausted cities in China.

http://www.gov.cn/ztzl/2008-09/19/content_1100369.html (2008-09-19) 
[48]H.B. Duan, G.P. Zhang, S.Y Wang, Y. Fan. Integrated benefit-cost analysis between China's optimal adaptation and targeted mitigation. Ecol. Econ., 2019; 160: 76-86.

[49]H.B. Duan, G.P. Zhang, S.Y Wang, Y. Fan. Review on robust climate economic research: Multi-model comparison analysis. Environ. Res. Lett., 2019; 14(3): 033001.

[50]Zhou Y, Shan YL, Liu GS, Guan DB. Emissions and low-carbon development in Guangdong-Hong Kong-Macao Greater Bay Area cities and their surroundings. Appl energy 2018; 228: $1683-1692$.

[51] Xu XWH, Huo H, Liu JR, Shan YL, Li Y, Zheng HR, Guan DB, Ouyang ZY. Patterns of $\mathrm{CO}_{2}$ emissions in 18 central Chinese cities from 2000 to 2014. J Clean Prod 2018; 172: 529-540. 